American Journal of Environmental Sciences 7 (4): 295-305, 2011

ISSN 1553-345X

(C) 2011 Science Publications

\title{
Removal of Hydrogen Sulphide from Water
}

\author{
S. Edwards, R. Alharthi and A.E. Ghaly \\ Department of Process Engineering and Applied Sciences, \\ Dalhousie University Halifax, Nova Scotia, Canada
}

\begin{abstract}
Problem statement: The concentration of $\mathrm{H}_{2} \mathrm{~S}$ in groundwater is a significant problem in various areas across Canada. Hydrogen sulphide dissolves in ground water imparting undesirable taste and irritating rotten egg smell which makes it unpalatable. Ingestion of sulphides through drinking water can result in stomach discomfort, nausea and vomiting. Humans exposed to high concentrations of $\mathrm{H}_{2} \mathrm{~S}$ for prolonged periods show symptoms of gastro-intestinal upset, anorexia, nausea, somnolence, amnesia, loss of consciousness, delirium, hallucinations, difficulty in swallowing, low blood pressure, slowing of heart rate, double vision and epileptiform convulsions. Hydrogen sulphide in blood is rapidly oxidized by molecular oxygen and thus reduces the oxidation power of haemoglobin. Unoxidized hydrogen sulphide can act upon the central nervous system and cause either paralysis or respiratory failure. It is therefore, necessary to have a very low concentration of $\mathrm{H}_{2} \mathrm{~S}$ in the water. Approach: An automatic system for the addition of $\mathrm{KMnO}_{4}$ and removal of hydrogen sulphide from ground water was developed and tested. The system consisted of a freshwater tank, a pump, a chemical storage tank, a solenoid valve, a photocell and electronic circuit, a drainage tank, a filter and a set of valves. It was possible to use a photocell to detect the presence of excess $\mathrm{KMnO}_{4}$ in the system and to control the addition of $\mathrm{KMnO}_{4}$ into the system. Results: The system accomplished complete removal of hydrogen sulphide in the range of 1-30 ppm. The present system utilizes on/off control for the addition of the chemical. The amount of $\mathrm{KMnO}_{4}$ needed as a percentage of the amount used was in the range of 5-28\%. Conclusion: The photocell and circuit could be used to add an amount of chemical that is constantly proportional to the amount of hydrogen sulphide in the water. The control of a positive displacement chemical feed pump would be an ideal application for this system. The speed of the pump could be controlled in such a manner that would allow a very small excess amount of potassium permanganate to be maintained in the system.
\end{abstract}

Key word: Ground water, drinking water, greensand filter, $\mathrm{H}_{2} \mathrm{~S}, \mathrm{KMnO}_{4}$, photocell, solenoid valves, gastro-intestinal upset, hydrogen sulphide, potassium permanganate, meguma supergroup, lower turbidity

\section{INTRODUCTION}

The concentration of $\mathrm{H}_{2} \mathrm{~S}$ in groundwater is a significant problem in various areas across Canada in areas having geological strata of sedimentary origin as seen in Fig. 1 (Health Canada, 1992; NRC, 2008). Areas in Canada that have reoccurring problems of hydrogen sulphide contamination of groundwater are illustrated in Fig. 2. There are some problems in areas near farm communities and swampy areas in Ontario and the level of contamination may depend on the water table level (Sparling and Hennick, 1974; Macdonald, 2003). In Nova Scotia, the problem is known to exist in Beaver bank, Upper Sackville and Hammonds Plains (Mellet, 2010). These areas are underlain by sulphide bearing minerals from the Meguma Supergroup and the Cunard Formation geological groups (Goodwin et al., 2008).
Hydrogen sulphide dissolves in ground water imparting undesirable taste and irritating rotten egg smell which makes it unpalatable.

Since humans are able to detect a concentration as low as $0.003-0.2 \mathrm{ppm}$, a high degree of treatment is needed to render the water drinkable (EPA, 2003). Ingestion of sulphides through drinking water can result in stomach discomfort, nausea and vomiting (Health Canada, 1992). Drinking water contaminated with sulphide can be fatal at a high enough dosage (10-15g sodium sulphide). Humans exposed to high concentrations of hydrogen sulphide show symptoms of gastro-intestinal upset, anorexia, nausea, somnolence, amnesia, loss of consciousness, delirium, hallucinations, difficulty in swallowing, low blood pressure, slowing of heart rate, double vision and epileptiform convulsions (Grey, 1961).

Corresponding Author: Abdel Ghaly, Department of Process Engineering and Applied Sciences, Dalhousie University, Halifax, Nova Scotia, Canada Tel: (902) 494-6014 


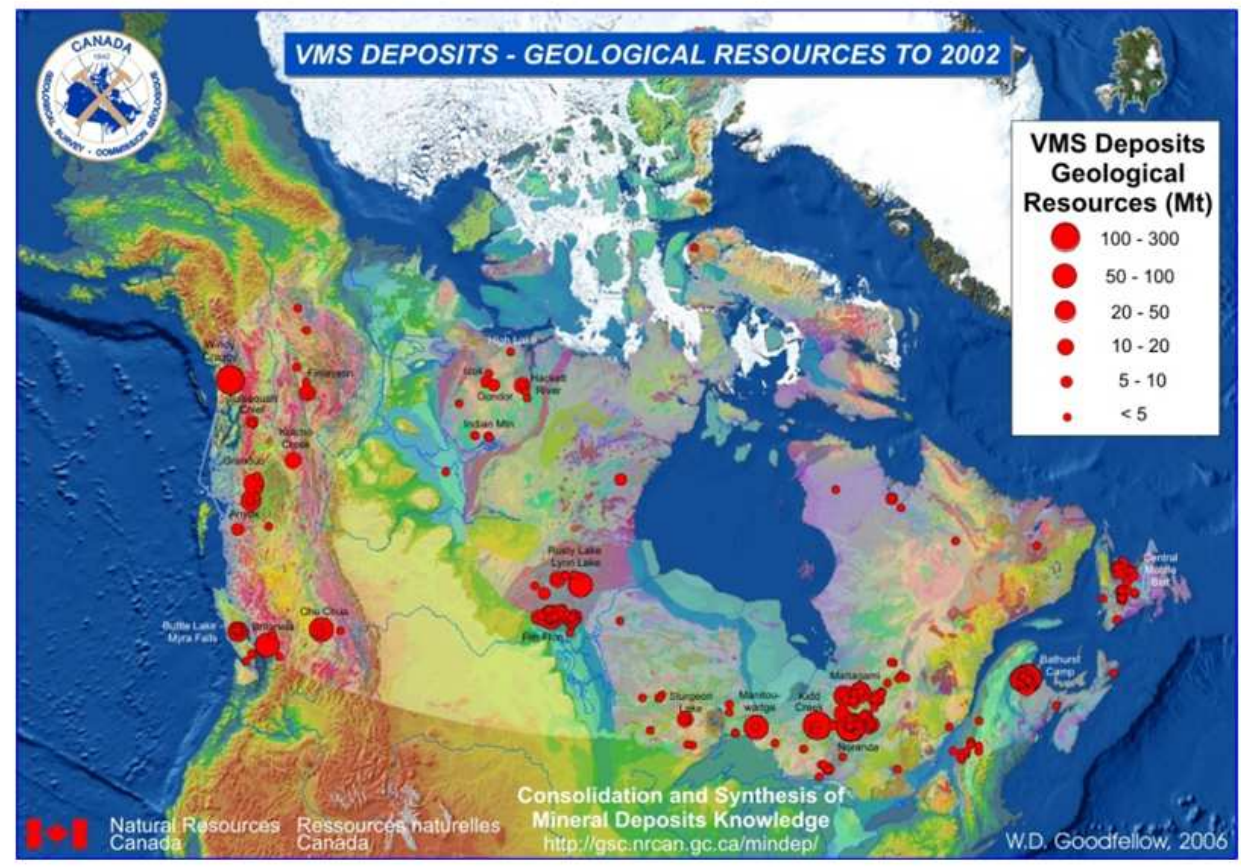

Fig. 1: Volcanogenic Massive Sulphide (VMS) deposits in Canada (NRC, 2008)

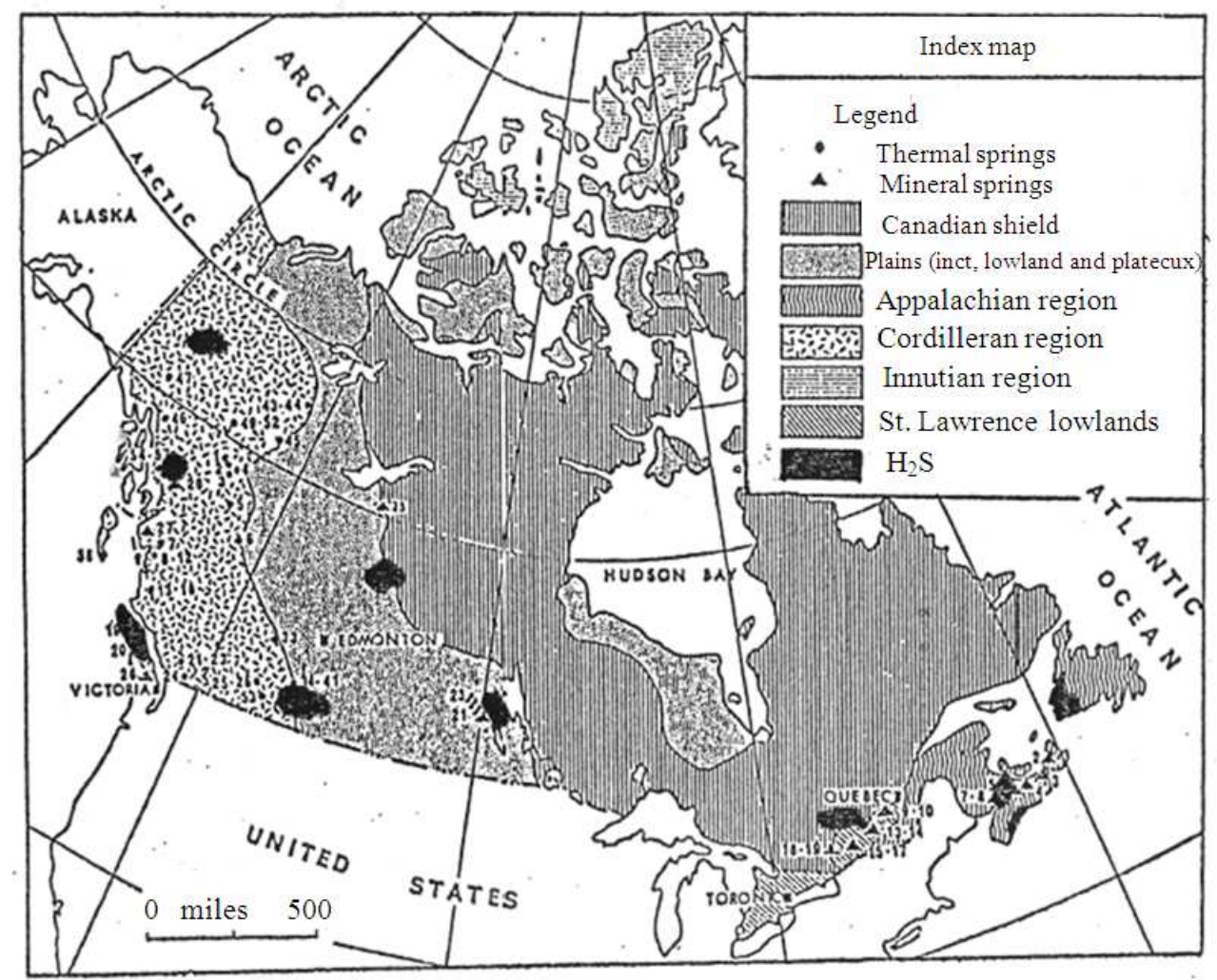

Fig. 2: Thermal and mineral springs of Canada with known $\mathrm{H}_{2} \mathrm{~S}$ contamination (EMRC, 1984) 
Am. J. Environ. Sci., 7 (4): 295-305, 2011

However, large doses cause odour that would alert an individual to the presence of an unnatural substance in drinking water and sulphide poisoning cases occur most commonly from inhalation. Sulphide can be detected by smell at a level of $11 \mu \mathrm{g} \mathrm{m}^{-3}$, it numbs a person's sense of smell at a level of $140 \mathrm{mg} \mathrm{m}^{-3}$ and above $700 \mathrm{mg} \mathrm{m}^{-3}$ inhalation can very quickly be fatal (Chou, 2003). Hydrogen sulphide in blood is rapidly oxidized by molecular oxygen and thus reduces the oxidation power of haemoglobin. Unoxidized hydrogen sulphide can act upon the central nervous system and cause either paralysis or respiratory failure (Grey, 1961).

It is, therefore, desirable to have a very low concentration of $\mathrm{H}_{2} \mathrm{~S}$ in water because of its high toxicity to animals and humans and corrosivity problems (WHO, 2003). The Nova Scotia Department of Health sets the maximum allowable concentration of $\mathrm{H}_{2} \mathrm{~S}$ in drinking water at $0.05 \mathrm{ppm}$ (NSDH, 2009). There are several techniques for removing $\mathrm{H}_{2} \mathrm{~S}$ from water including aeration, ozonation, ion exchange, reverse osmosis, biological treatment and chemical oxidation (Janssen et al., 1999; Einarsen et al., 2000).

Mechanisms of $\mathrm{H}_{2} \mathrm{~S}$ generation: Figure 3 shows the various mechanisms of $\mathrm{H}_{2} \mathrm{~S}$ generation. Schlesinger (1966) stated that under acidic aerobic conditions and high moisture content, the calcium in limestone $\left(\mathrm{CaCO}_{3}\right)$ interacts with the sulphur in pyrite $\left(\mathrm{FeS}_{2}\right)$ to form gypsum $\left(\mathrm{CaSO}_{4}\right)$, the iron is oxidized to form ferric oxide $\left(\mathrm{Fe}_{2} \mathrm{O}_{3}\right)$ and the carbonate is converted to carbon dioxide $\left(\mathrm{CO}_{2}\right)$ Eq. 1:

$8 \mathrm{CaCO}_{3}+4 \mathrm{FeS}_{2}+7 \mathrm{O}_{2}$

$\rightarrow 8 \mathrm{CaSO}_{4}+2 \mathrm{Fe}_{2} \mathrm{O}_{5}+8 \mathrm{CO}_{2}$

When the environment becomes anaerobic the sulphate is reduced to hydrogen sulphide $\left(\mathrm{H}_{2} \mathrm{~S}\right)$ by sulphur reducing bacteria in the presence of organic matter as follows (Faust and Osman, 1983; Lloyd, 2006) Eq. 2:

$$
2 \mathrm{CH}_{2} \mathrm{O}+\mathrm{SO}_{4}{ }^{2-} \stackrel{\text { Bacteria }}{\longrightarrow} \mathrm{H}_{2} \mathrm{~S}+2 \mathrm{HCO}_{3}^{-}
$$

Hydrogen sulphide may also develop under anaerobic conditions as a result of putrefaction of sulphur containing amino acids such as cysteine or methionine (Chou; 2003; EPA, 2003; Li et al., 2009). Mammals can produce hydrogen sulphide through a number of different pathways (Fig. 4). According to Kamoun (2004) and Li et al. (2009), these pathways are enzymatically catalyzed by Cystathionine $\beta$ Synthetase (CBS), Cystathionine $\gamma$ Lyase (CSE) or Cysteine Amino Transferase (CAT) Eq. 3-5:
Homocysteine + serine

$\stackrel{\text { cystathionine } \beta \text { synthetas }}{\longrightarrow}$ Cystathionine $+\mathrm{H}_{2} \mathrm{O}$

Cystathionine $+\mathrm{H}_{2} \mathrm{O} \stackrel{\text { cystathionine } \gamma \text { lyase }}{\longrightarrow}$

$\mathrm{L}-$ Cysteine $+\alpha$ Ketobutyrate + Pyruvate

L-Cysteine $\rightarrow \mathrm{H}_{2} \mathrm{~S}$

Water with high sulphide levels is generated by a number of industrial facilities such as petrochemical plants, tanneries, viscose rayon manufacturers and study and pulp plants (Janssen et al., 1999; Rinzema et al. 1988; Brimblecombe and Lein, 1989). It has also been reported that $\mathrm{H}_{2} \mathrm{~S}$ is produced in hot water tanks (ADOA, 2007). This is a result of the inclusion of an anti-corrosion precaution. Often a magnesium based rod is included to act as a sacrificial anode to prevent corrosion. When oxidized, this material releases a greater amount of electrons than is needed to protect the exposed steel from corrosion. The excess electrons provide an energy source for sulphate reducing bacteria present in the water leading to the production of $\mathrm{H}_{2} \mathrm{~S}$.

Ionic speies of $\mathbf{h}_{2} \mathbf{s}$ in ground water: The existence of ionic species of hydrogen sulphide in groundwater is highly dependent on $\mathrm{pH}$. Major sulphur species present in ground water are Hydrogen Sulphide $\left(\mathrm{H}_{2} \mathrm{~S}\right)$, bisulfide (HS ${ }^{-}$) and sulphide $\left(\mathrm{S}^{2-}\right)$. Changes in the concentrations of hydrogen sulphide, bisulfide and sulphide can be affected by $\mathrm{pH}$ changes as shown in Fig. 5. At a low $\mathrm{pH}$ (5-6), $\mathrm{H}_{2} \mathrm{~S}$ is the dominant species but with a slight increase in $\mathrm{pH}^{-}(7-9)$, the $\mathrm{HS}^{-}$becomes the dominant species. At a high $\mathrm{pH}(>9)$, the $\mathrm{S}^{2-}$ becomes the dominant species.

Removal of $\mathbf{S}^{\mathbf{2}-}$ from water: Thompson et al. (1995) reported that reduced species of sulphur $\left(\mathrm{S}^{2-}\right)$ can be effectively oxidized by chlorine in aqueous solutions:

$\mathrm{Cl}_{2}+\mathrm{S}^{2-} \rightarrow 2 \mathrm{Cl}^{-}+\mathrm{S}^{0}$

$4 \mathrm{Cl}_{2}+\mathrm{S}^{2-}+4 \mathrm{H}_{2} \mathrm{O} \rightarrow 8 \mathrm{H}^{+}+8 \mathrm{Cl}^{-}+\mathrm{SO}_{4}^{2-}$

Equation 6 represents an instantaneous primary reaction to form elemental sulphur $\left(S^{0}\right)$ while Eq. 7 represents the possible oxidation of reduced sulphur to form sulphate $\left(\mathrm{SO}_{4}{ }^{2-}\right)$. The factors affecting the ratio of $\mathrm{S}^{0}$ to $\mathrm{SO}_{4}{ }^{2-}$ are $\mathrm{pH}$, temperature, time, concentration and flow rate. 
Am. J. Environ. Sci., 7 (4): 295-305, 2011

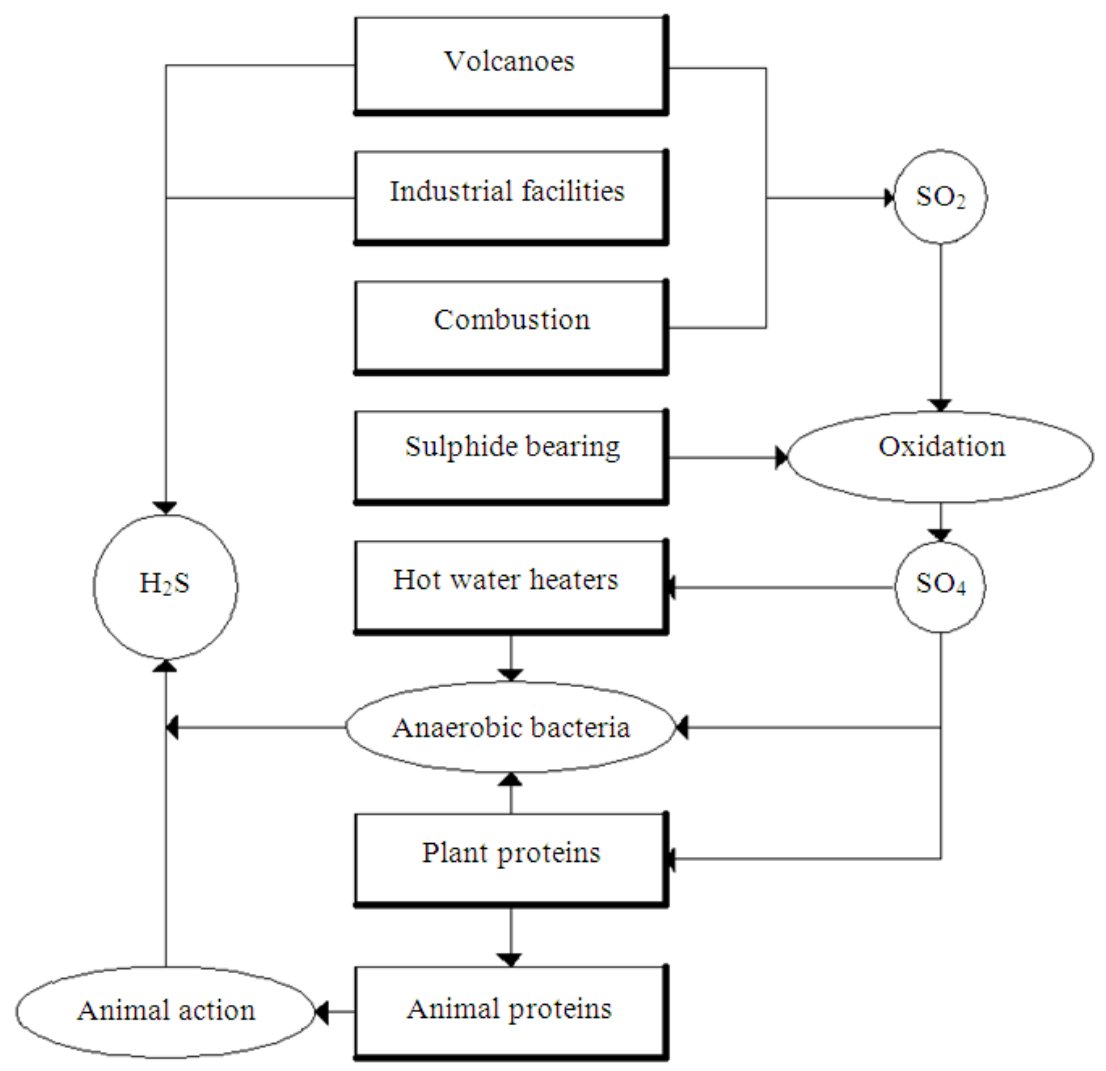

Fig. 3: Mechanisms of $\mathrm{H}_{2} \mathrm{~S}$ production

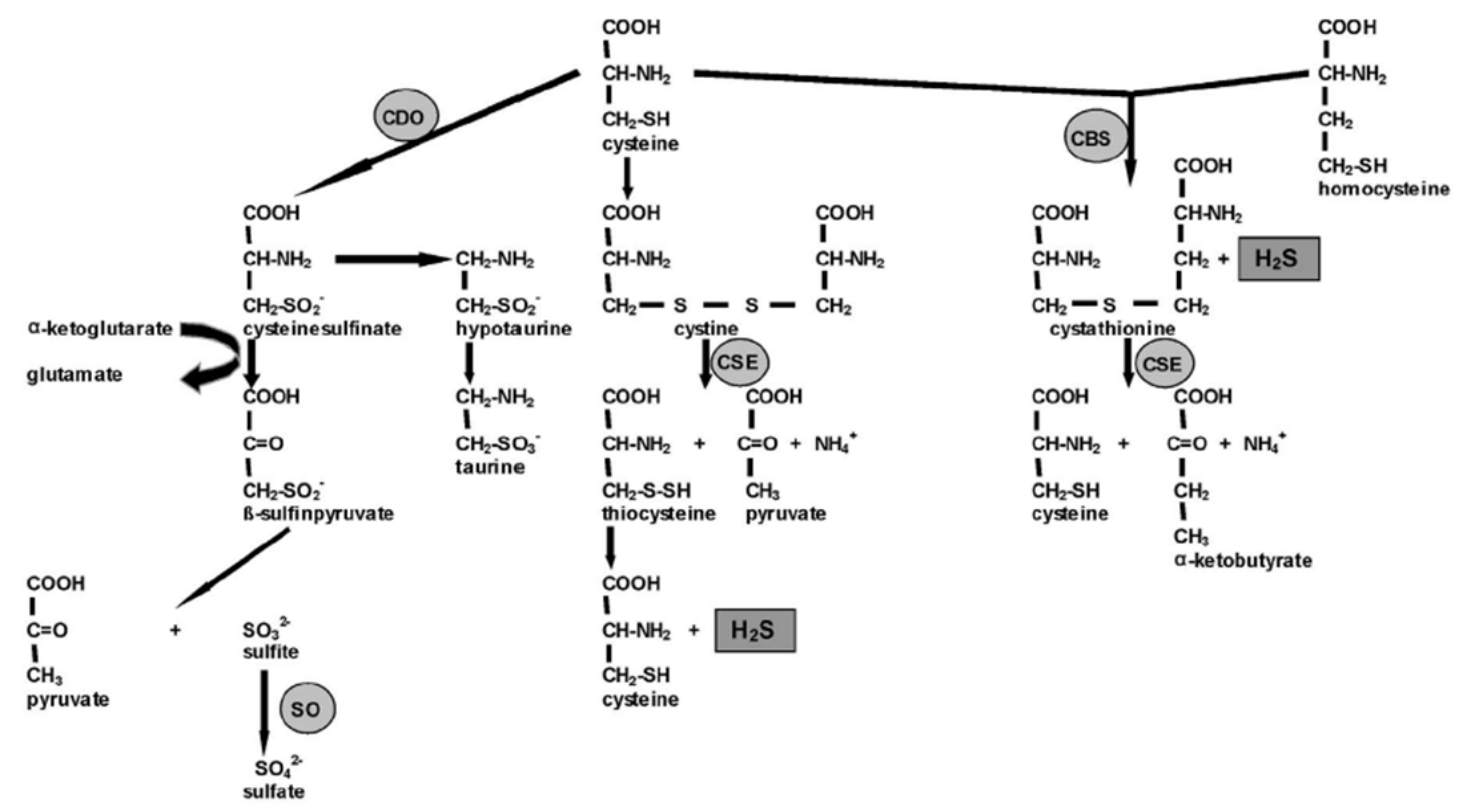

Fig. 4: Hydrogen sulphide production pathways in mammals (Lowicka and Beltowski, 2007) 


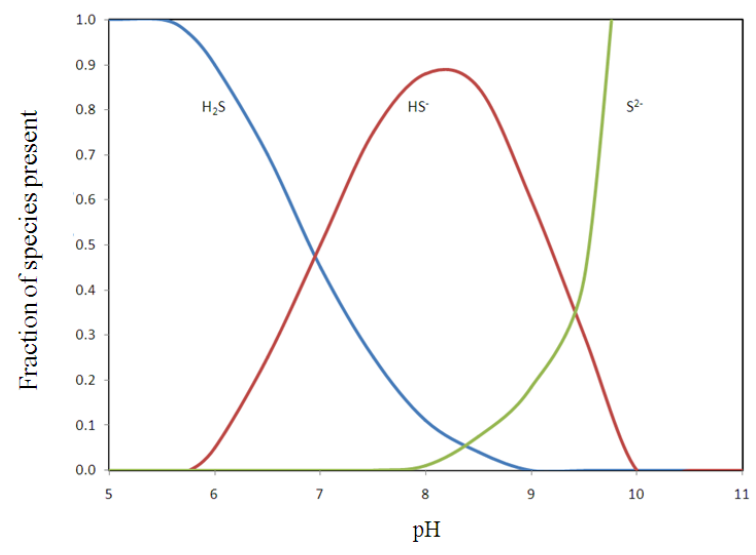

Fig. 5: Ionic Species of Hydrogen Sulphide (Thompson et al., 1995)

The authors stated that chlorine oxidation follwed by physical filtration is more reliable than conventional oxidation with air for a number of reasons: (a) without aeration, the water will be less saturated with oxygen and, therefore, less corrosive, (b) the compactness of the microfiltration unit and the efficiency of particle removal make it a viable option for $\mathrm{H}_{2} \mathrm{~S}$ removal for individual houses (consisting of only a well and a storage tank) and (c) offensive odours from $\mathrm{H}_{2} \mathrm{~S}$ would be mitigated because there is no degassing in the process. Chlorine oxidation also has the advantage of eliminating odour and corrosion problems as well as killing any sulphur reducing bacteria. However, an activated carbon filter must be used to remove the objectionable chlorine taste and odour from water.

Removal of $\mathrm{H}_{2} \mathrm{~S}$ from water: The removal techniques of $\mathrm{H}_{2} \mathrm{~S}$ from water include aeration, ion exchange, reverse osmosis, ozonation and chemical treatments. There are three types of aeration used to remove $\mathrm{H}_{2} \mathrm{~S}$ from water: (a) spray aeration where pressurized water is force into the air through spray nozzles, (b) forced draft aeration where sheets of water fall over a series of wood baffles from a predetermined height and (c) air diffusion aeration where air bubbles are forced through a body of water. However, removal of $\mathrm{H}_{2} \mathrm{~S}$ by aeration is not necessarily ideal for all situations. It requires an acidic $\mathrm{pH}$, long contact times and, by proxy, a high energy input (Lemley et al., 1999). Furthermore, $\mathrm{H}_{2} \mathrm{~S}$ is difficult to remove in alkaline water because most of $\mathrm{H}_{2} \mathrm{~S}$ is present in the form of $\mathrm{HS}^{-}$and $\mathrm{H}^{+}$ions.

Thompson et al. (1995) reported that decreasing the $\mathrm{pH}$ of the water entering an aeration system can improve hydrogen sulphide removal efficiency and lower turbidity levels but may result in the formation of disinfection by-products that increase copper corrosion rates. They also stated that removal of hydrogen sulphide by aeration is not an efficient method because the presence of sulphur in the form of hydrogen sulphide depends on the $\mathrm{pH}$ and chemical oxidation of bisulfide with chlorine is significantly slower than the oxidation of hydrogen sulphide and results in high turbidity. They suggested the use of coagulants followed by microfiltration to remove the disinfection by product precursor material and improve the finished water quality.

Montgomery (1985) reported on a treatment for $\mathrm{H}_{2} \mathrm{~S}$ removal using a cascade tray aerator on the top of a ground water storage tank. The process produced high levels of turbidity and an offensive rotten egg odour. The turbidity resulted from the oxidation of hydrogen sulphide to elemental Sulphur $\left(S^{0}\right)$. The removal efficiency was only $20 \%$ at ambient $\mathrm{pH}$ and temperature and the remaining hydrogen sulphide was oxidized by chlorine and sent to the storage tank. The turbidity created by elemental sulphur interfered with the disinfection process and created issues in the distribution pipes.

Both ion exchange and reverse osmosis are complicated and do not produce the desired results (Brimblecombe and Lein, 1989). Ozone oxidation of $\mathrm{H}_{2} \mathrm{~S}$ is very effective treatment but it is very costly to set up a treatment facility (Kato et al., 2005). Chemical methods use oxidizing agents to oxidize $\mathrm{H}_{2} \mathrm{~S}$ (Willey et al., 1964; Dohnalek and Fitzpatrick, 1983). Wille et al. (1964) and Dohnalek and Fitzpatrick (1983) used potassium permanganate to oxidize $\mathrm{H}_{2} \mathrm{~S}$ into sulfate Eq. 8:

$4 \mathrm{KMnO}_{4}+2 \mathrm{H}_{2} \mathrm{~S} \rightarrow 2 \mathrm{~K}_{2} \mathrm{SO}_{4}$

$+2 \mathrm{MnO}+2 \mathrm{MnO}_{2}+2 \mathrm{H}_{2} \mathrm{O}$

Cadena and Peters (1988) stated that the interaction between oxidizing agents such as potassium permanganate $\left(\mathrm{KMnO}_{4}\right)$ and hydrogen sulphide is very rapid and produces solids in the form of flocculate particles of manganese oxide $\left(\mathrm{MnO}_{2}\right)$ and elemental sulphur $\left(\mathrm{S}^{0}\right)$ which can be removed by a sand filter. This reaction proceeds according to the following Eq. 9:

$3 \mathrm{H}_{2} \mathrm{~S}+2 \mathrm{KMnO}_{4} \rightarrow 3 \mathrm{~S}^{0}+2 \mathrm{H}_{2} \mathrm{O}$

$+2 \mathrm{MnO}_{2}+2 \mathrm{KOH}$ If $\mathrm{pH}<7.5$

The advantages of converting $\mathrm{H}_{2} \mathrm{~S}$ into elemental Sulphur $\left(\mathrm{S}^{0}\right)$ rather than sulphate $\left(\mathrm{SO}_{4}{ }^{-}\right)$are: (a) the process is much faster, (b) less sludge is produced, (c) no sulphate or thiosulfate is discharged, (d) the possibility of reusing the sulphur for the production of $\mathrm{H}_{2} \mathrm{SO}_{4}$ and biobleaching processes, (e) no oxygen is required and (f) less energy is required (Janssen et al., 1989; Tichy et al., 1994). Thomson et al., (1995) 
reported that the use of microfiltration after chemical oxidation can provide an excellent alternative for $\mathrm{H}_{2} \mathrm{~S}$ removal when proper chemical conditions are obtained to maximize the conversion of $\mathrm{H}_{2} \mathrm{~S}$ and $\mathrm{HS}^{-}$to elemental Sulphur $\left(\mathrm{S}^{0}\right)$.

Davis and Fackler (1983) indicated that when green sand is used with $\mathrm{KMnO}_{4}$, a product (manganese greensand) is produced in which the sand particles are impregnated with manganese oxide which serves as a catalyst for oxidation and removal of hydrogen sulphide.

However, hydrogen sulphide concentrations in groundwater vary with time which makes dosing of chemical oxidants difficult to control. The use of green sand is proposed as a filter medium for rapid filtration of the flocculent particles. The green sand is a mineral (glauconate) which has a catalytic effect on the oxidation-reduction reaction between hydrogen sulphide and potassium permanganate and the capacity to absorb excess manganese ions remaining in the water after the oxidation of hydrogen sulphide is completed. Thus, the manganese oxide coating on the green sand may continuously be regenerated during filtration. However, there is a lack of information regarding building and operating a continuously regenerated green sand filter for the removal of hydrogen sulphide from ground water supplies in private homes.

Removal of $\mathrm{S}^{2-}$ from Water.

\section{MATERIALS AND METHODS}

The specific objectives of this study were to determine: (a) the operating parameters of green sand filters (water flow rate, rate of chemical addition, pressure-build-up and frequency of back washing) and (b) the interaction between the filter medium (green sand) and filter efficiency.

System design: The chemical application-filtration system consists of a freshwater tank, a pump, a chemical storage tank, a solenoid valve, a photocell device, a drainage tank, a green sand filter and a set of valves (Fig. 6). The contaminated water is pumped directly from the well or from the fresh water tank to the green sand filter passing through the photo cell device at which point an impulse is sent to the solenoid valve to inject some potassium permanganate into the solution until it becomes pink in color. The pink solution passes through the greensand filter where the precipitated sulphur and the excess permanganate are removed. The clear odourless water is collected at the effluent end of the filter and is fit for human consumption.
Photocell: The photocell device was designed as an online device in series with the water supply piping system allowing the water to pass through it and the light to pass through the water onto the photocell. It was constructed of a clear Plexiglas container of $2 \mathrm{~cm}$ width $\times 10 \mathrm{~cm}$ length $\times 10 \mathrm{~cm}$ height (Fig. 7a). The water entered the Plexiglas container from one side at a height of $1 \mathrm{~cm}$ from the bottom and exited from the opposite side at a height of $0.5 \mathrm{~cm}$ from the top. This allowed a constant water level inside the container. Plastic fittings of $0.5 \mathrm{~cm}$ diameter were connected to the container at the inlet and outlet. The black box was constructed of $2 \mathrm{~cm}$ thick plywood and has a removable cover. The inside of the box was painted with a flat black paint to minimize reflection. The Plexiglas container was enclosed inside a black wooden box as shown in Fig. 7b. The photocell was placed on one side of the Plexiglas container and the light bulb was placed on the other side such that the rays were incidental on the photo cell. A cadmium sulphide photocell was used to detect the light directed through the fluid medium. The light rays were perpendicular to the cell wall to prevent the light from reflecting off the cell wall. The voltage across the photocell is subjected to change with light intensity (concentration of $\mathrm{KMnO}_{4}$ ). When the light intensity is great, the resistance of the photo cell is small and when the light intensity is weak the resistance of the photocell is large. The light bulb was powered by a 6 volt power source driven from an AC adapter (120 VAC/6 VDC). Figure 8 shows the schematic of the circuit used for measuring the voltage.

Greensand filter: The filter body was made of a $70 \mathrm{~cm}$ long Plexiglas cylinder of $20 \mathrm{~cm}$ inside diameter and 1 $\mathrm{cm}$ wall thickness (Fig. 9). A circular plate of $22 \mathrm{~cm}$ diameter and $1 \mathrm{~cm}$ thickness was glued to the bottom of the cylinder. A $2.5 \mathrm{~cm}$ diameter plastic fitting, threaded into the center of the plate, was used as the outlet.

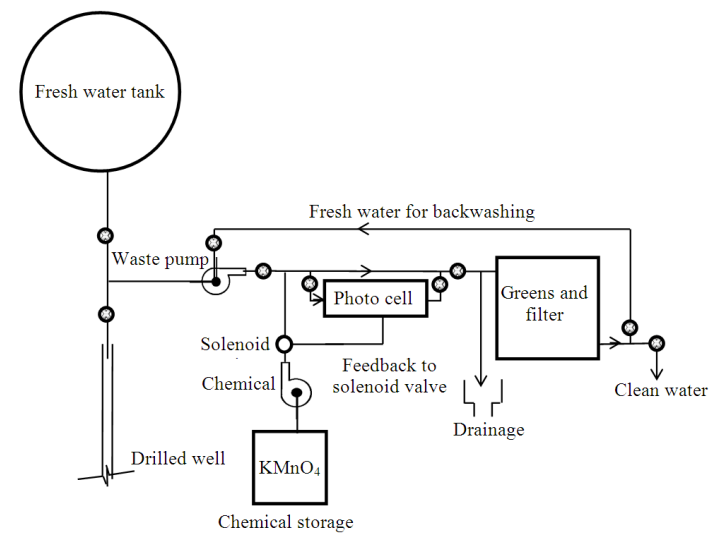

Fig. 6: General lay out for the chemical application filtration system 


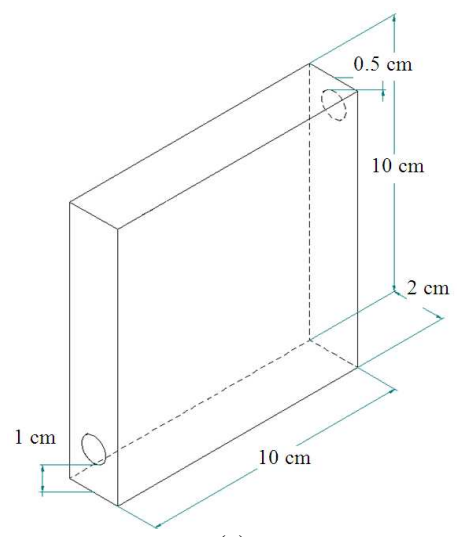

(a)

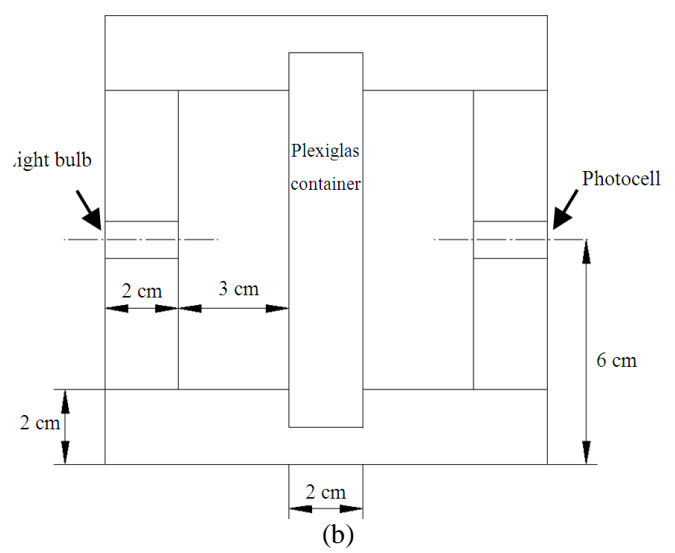

Fig. 7: Plexiglas container and black box (a) Plexiglas container (b) The flow through Plexiglas container in black box

A $2.5 \mathrm{~cm}$ ball valve was connected to the fitting. A 20 $\mathrm{cm}$ diameter fine screen (hole size smaller than the sand particle size) was glued onto the inside of the circular plate to avoid losing the sand through the outlet. The top cover was also made of a Plexiglas circular plate of $22 \mathrm{~cm}$ diameter and $1 \mathrm{~cm}$ thickness. A $2.5 \mathrm{~cm}$ plastic fitting, threaded into the center of the plate, was used as an inlet. A $20 \mathrm{~cm}$ diameter fine screen was glued to the inside of the cover plate. The cover plate was fixed to the top collar of the cylinder using 6 plots with wing nuts. An O-ring was used under the cover to provide a good seal. The filter was filled with green sand before fixing the cover. The greensand is regenerative, the particles do not lose their ability to oxidize the excess permanganate in the incoming solution. However, after sufficient filter use, the filter may become clogged with the flour of sulphur that was removed from the contaminated water. The method of removing these particles of sulphur from the filter is known as backwashing. This is accomplished by reversing the flow of the water through the filter.

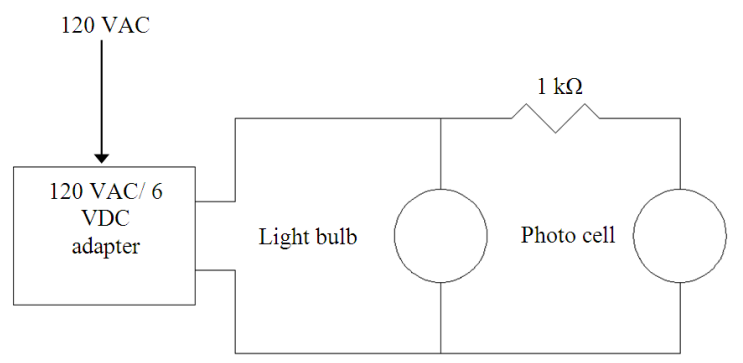

Fig. 8: Circuit used to power the light bulb and photocell

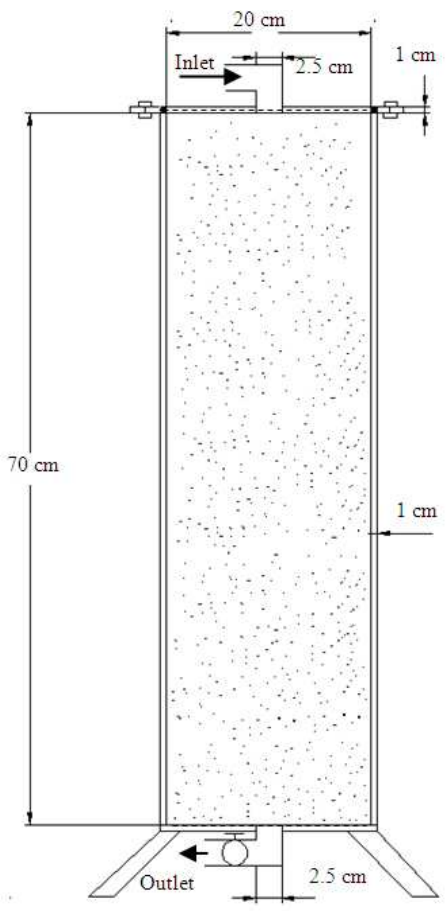

Fig. 9: Greensand filter dimensions

Drainage container: The sulphur contaminated wastewater was collected in a drainage container. The container was made of a $50 \mathrm{~cm}$ long Plexiglas cylinder of $20 \mathrm{~cm}$ diameter and $1 \mathrm{~cm}$ wall thickness. The bottom and top of the cylinder were made of circular Plexiglas plates of $20 \mathrm{~cm}$ diameter and $1 \mathrm{~cm}$ thickness. The sulphur can be collected by passing the waste solution through filter study.

Solenoid valves: The solenoid valve controls the flow of $\mathrm{KMnO}_{4}$ into the system in order to maintain an excess of $\mathrm{KMnO}_{4}$ at a concentration of approximately10 -15 ppm. An excess of $\mathrm{KMnO}_{4}$ in the order of $5 \mathrm{ppm}$ gives rise to a pink color in the solution. 


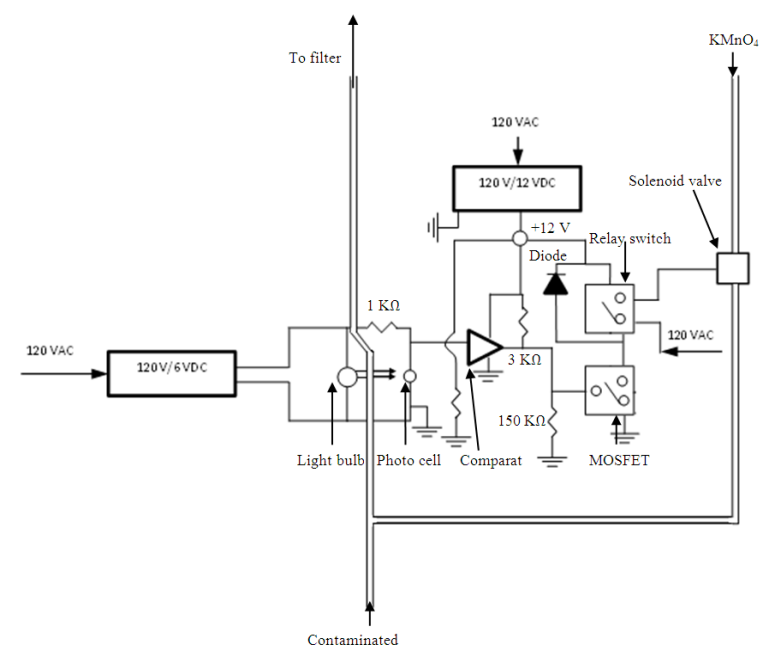

Fig. 10: Control system

Control system: The control circuit was designed to receive and interpret the voltage output from the photocell and determined when the solenoid valve should be turned on or off. It is capable of delivering 120 volts to energize the valve and turn on the pump to deliver the $\mathrm{KMnO}_{4}$ to the water line. The two main components of the circuit are a voltage comparator and a relay switch (Fig. 10).

The voltage comparator has the capability of accepting the voltage output of the photocell and comparing it to a reference voltage that can be varied depending on the system use and the level of $\mathrm{KMnO}_{4}$. If the output voltage of the cell is less than the reference voltage, it will be necessary to energize the solenoid valve and the comparator sends a 12 volt signal to its output. If the out voltage from the photocell is greater than the reference voltage the 12 volt output signal is stopped. Potassium permanganate concentrations of 10$15 \mathrm{ppm}$ will have specific voltages associated with them. Assume that $\mathrm{V}_{1}$ is associated with $10 \mathrm{ppm}$ $\mathrm{KMnO}_{4}$ and that $\mathrm{V}_{2}$ is associated with $15 \mathrm{ppm} \mathrm{KMnO}_{4}$. When the voltage across the photo cell is greater than $\mathrm{V}_{1}$ but less than $\mathrm{V}_{2}$, the system is in equilibrium. If the voltage across the photo cell is greater than $\mathrm{V}_{1}$, an electrical impulse is sent to the solenoid valve allowing more $\mathrm{KMnO}_{4}$ to be added. If the voltage across the photo cell is greater than $\mathrm{V}_{2}$, an electrical impulse is sent to the solenoid valve halting the addition of $\mathrm{KMnO}_{4}$ into the system. This will ensure that there will always be an excess of $\mathrm{KMnO}_{4}$ present in the system. As a result all hydrogen sulphide that is in the water will be precipitated as elemental sulphur and manganese oxide. This solution will then be passed through the green sand filter allowing it to remove the flour of sulphur and manganese oxide.

The 12 volt output signal is used to power a 12 VDC/120 VAC relay switch. A MOSFET receives the 12 volt signal from the comparator and applies it across the relay switch allowing the solenoid valve to be energised. A diode is used to allow the current to flow only in one direction. This prevents high voltage from going back through the circuit and possibly damaging some of the sensitive integrated circuits.

Experimental procedure: Photocell testing: A preliminary experiment was carried out to test the effectiveness of the photocell apparatus. First, $500 \mathrm{~mL}$ of $\mathrm{H}_{2} \mathrm{~S}$ standard solution (1500 ppm) was prepared. Then, $500 \mathrm{~mL}$ of $\mathrm{H}_{2} \mathrm{~S}$ aqueous solution, with $\mathrm{H}_{2} \mathrm{~S}$ concentration of $5 \mathrm{ppm}$ was prepared. Aliquots of 50 $\mathrm{mL}$ were put in ten $200 \mathrm{~mL}$ beakers. A 0.1 molar solution of $\mathrm{KMnO}_{4}$ was prepared by adding 0.7904 grams of pure $\mathrm{KMnO}_{4}$ into $50 \mathrm{ml}$ of distilled water. The solution was put in a titration burette. Two drops (0.1 $\mathrm{mL}$ ) of $\mathrm{KMnO}_{4}$ reacted with all the $\mathrm{H}_{2} \mathrm{~S}$ in each beaker. One extra drop of $\mathrm{KMnO}_{4}$ was added and the voltage across the photo cell was measured with the solution between the glass plates. The process was repeated for up to 20 extra drops of $\mathrm{KMnO}_{4}$. Readings for untreated $\mathrm{H}_{2} \mathrm{~S}$ and air in between the plates were also noted.

Filter evaluation: Hydrogen sulphide concentrations of $1,5,10,15$ and $30 \mathrm{ppm}$ were allowed to go through the system. The following measurements were taken: (a) initial concentration of hydrogen sulphide in the solution before it passes through the filter, (b) final concentration of hydrogen sulphide in the solution after it passes through the filter, (c) amount of potassium permanganate used and (d) the on/off ratio of the solenoid valve. The stoichiometric demand was calculated as per the molar ratio found in Eq. 3. Four moles of potassium permanganate are needed to oxidize three moles of hydrogen sulphide. A 500 ppm potassium permanganate solution was used during all of the test runs. Each run consisted of allowing 20 litres of the various concentrations of hydrogen sulphide to flow through the system.

\section{RESULTS}

Photocell: The objective of this experiment was to investigate the possibility of using a photocell to detect the pink color of excess $\mathrm{KMnO}_{4}$ and to use the resultant voltage to control the addition of $\mathrm{KMnO}_{4}$ to the water supply. 
Table 1: The voltage across the photo cell at various concentrations of $\mathrm{KMnO}_{4}$

\begin{tabular}{lll}
\hline Sample & Drops $\mathrm{KMnO}_{4}$ & Voltage \\
\hline Air & 0 & 2.62 \\
1 & 0 & 2.54 \\
2 & 2 & 2.63 \\
3 & 3 & 2.75 \\
4 & 4 & 2.83 \\
5 & 8 & 3.05 \\
6 & 10 & 3.08 \\
7 & 12 & 3.13 \\
8 & 15 & 3.24 \\
9 & 18 & 3.28 \\
10 & 20 & 3.33 \\
\hline
\end{tabular}

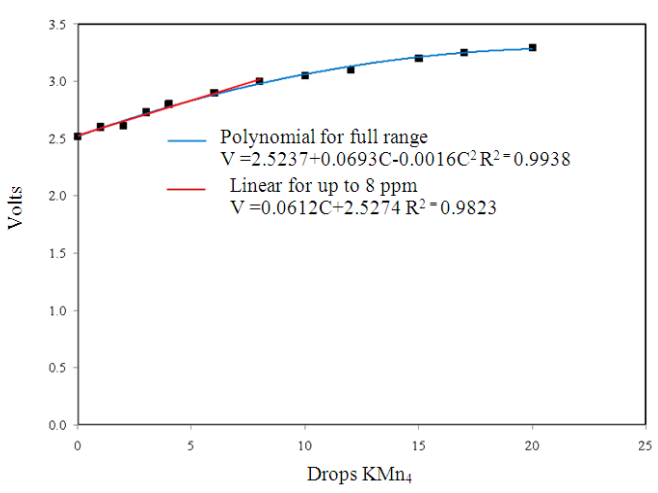

Fig. 11: The relationship between voltage and $\mathrm{KMnO}_{4}$ concentration

Hydrogen sulphide at a concentration of $5 \mathrm{ppm}$ was used in this experiment as this is the average value that might be expected in normal well water contaminated with hydrogen sulphide. Well water contaminations of hydrogen sulphide are normally less than $8 \mathrm{ppm}$ (Wellowner.org, 2009). $\mathrm{KMnO}_{4}$ reacted with $\mathrm{H}_{2} \mathrm{~S}$ producing a sulphur powder. Two drops of $\mathrm{KMnO}_{4}$ was the amount needed to react with all the $\mathrm{H}_{2} \mathrm{~S}$ present in each aliquot. The excess $\mathrm{KMnO}_{4}$ in the water ensured complete removal of $\mathrm{H}_{2} \mathrm{~S}$. The excess $\mathrm{KMnO}_{4}$ produced a pink color that was determined by the photocell as shown in Table 1. The relationship between the amount of excess $\mathrm{KMnO}_{4}$ and the measured voltage across the photo cell is presented in Fig. 11. This relationship appears to be linear within the range concerned, but the voltage tends to increase with a decreasing rate as the excess amount of $\mathrm{KMnO}_{4}$ becomes greater than 8 drops and the color becomes darker. The initial straight line relationship obtained is very satisfactory and it will be possible to use the output from the photocell to control a valve which will in turn control the amount of $\mathrm{KMnO}_{4}$ added to the contaminated well water.

Greensand filter: The results of the greensand filter test are shown in Table 2. For each concentration of $\mathrm{H}_{2} \mathrm{~S}$ (ranging from 1-30 ppm), total removal of the hydrogen sulphide was accomplished and the residual concentration of $\mathrm{H}_{2} \mathrm{~S}$ was 0 ppm.

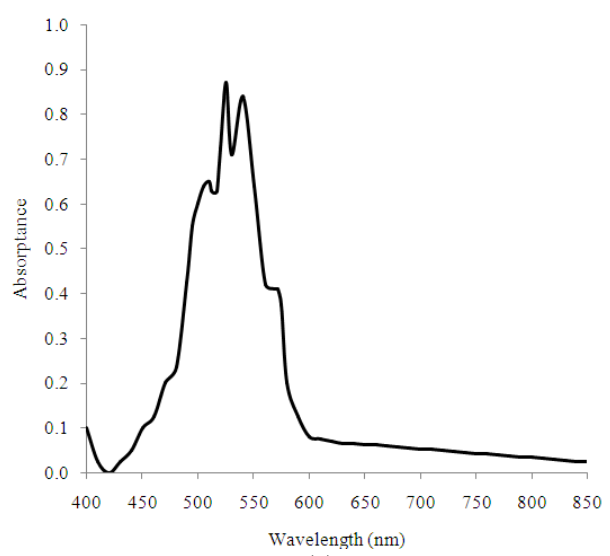

(a)

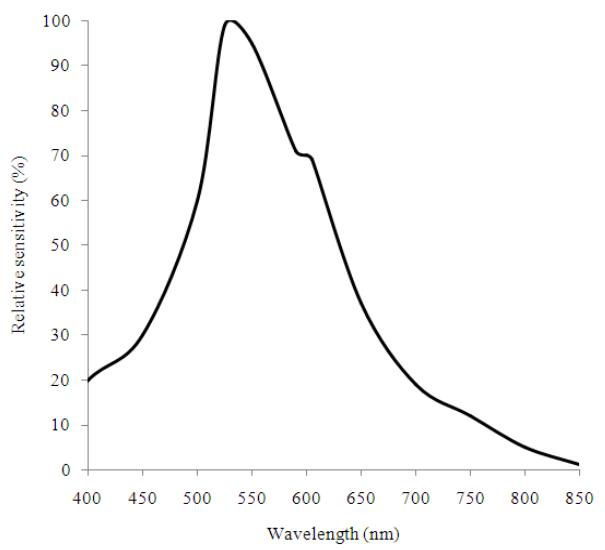

(b)

Fig. 12: Relative absorbance of $\mathrm{KMnO}_{4}$ in visible light and relative spectral response of $\mathrm{CdS}$ photocell Absorbance of $\mathrm{KMnO}_{4}$ (Gordon et al., 2002; Hilliard et al., 1999) Spectral response of CdS photocell (Twibright, 2009)

\section{DISCUSSION}

In passing through an absorbing medium, such as $\mathrm{KMnO}_{4}$, the light radiation will be diminished in power from an initial value of $\mathrm{P}_{\mathrm{o}}$ to a final value of $\mathrm{P}_{\mathrm{f}}$. Thus, the absorbance (A) can be defined as $\mathrm{P}_{\mathrm{o}} / \mathrm{P}_{\mathrm{f}}$ and is directly related to the absorbing species according to the following Beer's Law Eq. 10:

$\mathrm{A}=\mathrm{Ebc}$

Where:

$\mathrm{A}=$ The absorbance

$\mathrm{E}=\mathrm{A}$ constant dependent on wavelength

$\mathrm{b}=$ The width of the cell (absorbing medium)

$\mathrm{c}=$ The concentration of the absorbing medium 
Am. J. Environ. Sci., 7 (4): 295-305, 2011

Table 2: The stoichiometric and actual permanganate demand and the solenoid valve on/off ratio for various concentrations of hydrogen sulphide

\begin{tabular}{|c|c|c|c|c|c|c|c|c|c|}
\hline \multicolumn{3}{|c|}{ Initial $\mathrm{H}_{2} \mathrm{~S}$} & \multirow[b]{2}{*}{ (ppm) } & \multicolumn{2}{|c|}{ Final $\mathrm{H}_{2} \mathrm{~S}$ Stoichiometric } & \multicolumn{2}{|c|}{$\mathrm{KMnO}_{4}$ Actual } & \multirow{2}{*}{$\begin{array}{l}\text { Used } \\
(\%)\end{array}$} & \multirow{2}{*}{$\begin{array}{l}\text { Valve } \\
\text { On/off }\end{array}$} \\
\hline$(\mathrm{ppm})$ & (g) & $(\mathrm{mmol})$ & & (g) & $(\mathrm{mmol})$ & $(\mathrm{g})$ & $(\mathrm{mmol})$ & & \\
\hline 1 & 0.02 & 0.625 & 0 & 0.066 & 0.83 & 1.30 & 8.00 & 5.07 & $2 / 45$ \\
\hline 5 & 0.10 & 3.100 & 0 & 0.330 & 4.20 & 2.30 & 14.15 & 14.35 & $3 / 45$ \\
\hline 10 & 0.20 & 6.250 & 0 & 0.660 & 8.30 & 3.66 & 23.16 & 18.05 & $3 / 40$ \\
\hline 15 & 0.30 & 9.400 & 0 & 0.990 & 12.50 & 4.70 & 30.00 & 21.19 & $4 / 48$ \\
\hline 30 & 0.65 & 18.800 & 0 & 1.975 & 25.00 & 7.10 & 45.00 & 27.81 & $5 / 35$ \\
\hline
\end{tabular}

The variables $\mathrm{E}$ and $\mathrm{b}$ remain constant for a given absorbing medium such as $\mathrm{KMnO}_{4}$, leaving $\mathrm{A}$ as a function of $\mathrm{c}$ (concentration of $\mathrm{KMnO}_{4}$ ). $\mathrm{KMnO}_{4}$ in solution is deep purple in color. The peak absorbance wavelength of $\mathrm{KMnO}_{4}$ is 530-545 nm as shown in Fig. 12a (Gordon et al., 2002). The cadmium sulphide photocell used in this study is the most sensitive at a wavelength of $530 \mathrm{~nm}$ as shown in Fig. 12b (TwiBright, 2009). Thus, a small change in the concentration of $\mathrm{KMnO}_{4}$ would have a marked effect on the voltage output of the photocell.

The amount of potassium permanganate used increased with increasing concentration of hydrogen sulphide. The actual amount of potassium permanganate used is consistently higher than the stoichiometric amount of the chemical needed to oxidize the hydrogen sulphide as determined by the chemical Eq. 6. The system accomplished the purpose of removing the hydrogen sulphide from the water automatically and with $100 \%$ efficacy. The system was more efficient in $\mathrm{KMnO}_{4}$ usage at higher concentrations of sulphide. The amount of $\mathrm{KMnO}_{4}$ needed as a percentage of the amount used ranged from 5.07-27.81\%.

\section{CONCLUSION}

An automatic system for the addition of $\mathrm{KMnO}_{4}$ and removal of hydrogen sulphide from ground water was developed and tested. It was possible to use a photocell to detect the presence of excess $\mathrm{KMnO}_{4}$ in the system and to control the addition of $\mathrm{KMnO}_{4}$ into the system. The system accomplished complete removal of hydrogen sulphide in the range of 1-30 ppm. The present system utilizes on/off control for the addition of the chemical. The amount of $\mathrm{KMnO}_{4}$ needed to react with $\mathrm{H}_{2} \mathrm{~S}$ as a percentage of the amount used was in the range of 5-28\%. The photocell and developed circuit could be used to add an amount of chemical that is constantly proportional to the amount of $\mathrm{H}_{2} \mathrm{~S}$ in the water. The control of a positive displacement chemical feed pump would be an ideal application for this system. The speed of the pump could be controlled in such a manner that would allow a very small excess amount of potassium permanganate to be maintained in the system. The amount of the potassium permanganate used increased with increasing concentration of the hydrogen sulphide. The actual amount of potassium permanganate used is consistently higher than the stoichiometric amount of the chemical needed to oxidize the hydrogen sulphide as determined by the chemical Eq. 6. The system accomplished the purpose of removing the hydrogen sulphide from the water automatically and with $100 \%$ efficacy. The system was more efficient in $\mathrm{KMnO}_{4}$ usage at higher concentrations of sulphide. The amount of $\mathrm{KMnO}_{4}$ needed as a percentage of the amount used ranged from 5.07-27.81\%.

\section{ACKNOWLEDGEMENT}

This research was supported by the National Science and Engineering Research Council (NSERC) of Canada.

\section{REFERENCES}

ADOA, 2007. Removal of hydrogen sulphide from water. Agdex 716 (D14). Alberta Agriculture and Rural Development Farm Water Supply Section, Alberta Department of Agriculture. Calgary, Alberta, Canada.

Brimblecombe, P. and A.Y. Lein. 1989. Evolution of the Global Biogeochemical Sulphur Cycle. 1st Edn., Willey, New York, ISBN: 047192251X, pp: 241.

Cadena, F. and R.W. Peters, 1988. Evaluation of chemical oxidizers for hydrogen sulphide control. Water Pollut. Control Federat., 60: 1259-1263.

Chou, C.H.J.S., 2003. Hydrogen sulphide: Human health aspects. Concise International Chemical Assessment Document 53, World Health Organization, Geneva, Switzerland.

Davis, C.V. and R.B. Fackler, 1983. Removal of iron and manganese by ferrosand. $\mathrm{CR}$ and IR Hungerford and Terry Inc. Clayton, New Jersey, USA.

Dohnalek, D.A. and D.A. Fitzpatrick, 1983. The chemistry of reduced sulfur species and their removal from groundwater supplies. J. Am. Water Works Assoc., 75: 298-308. 
Einarsen, A.M., A. Esoy, A.I. Rasmussen, S. Bungum and M. Sveberg, 2000. Biological prevention and removal of hydrogen sulphide in sludge at Lillehammer Wastewater Treatment Plant. Water Sci. Technol., 41: 175-187.

EMRC, 1984. Canadian thermal and mineral springs. Energy, Mines and Resources Canada, Ottawa, Ontario, Canada.

EPA, 2003. Toxicological review of hydrogen sulphide. CAS No. 7783-06-4. Government printing office. Environmental Protection Agency. Washington, DC, USA.

Faust, S.D. and M.A. Osman, 1983, Chemistry of Water Treatment. 1st Edn., Ann Arbor Science, Wobura, MA, ISBN: 0250403889, pp: 723.

Goodwin, T.A., McIssac, E.M. and P.W.B. Friske, 2008. The North American Soil Geochemical Landscapes Project: Report on the 2008 Sampling Program and Preliminary Results. Report ME 2009-1. Nova Scotia Department of Natural Resources. Halifax, Nova Scotia, Canada. pp: 45-51

Gordon, J., A. James, S. Harman and K. Weiss, 2002. A film canister colorimeter. J. Chem. Educ., 79: 1005-1006. DOI: 10.1021/ed079p1005

Health Canada, 1992. Sulphide (as $\mathrm{H}_{2} \mathrm{~S}$ ), Health Canada, Ottawa, Ontario, Canada.

Hilliard, L.A., T. Lynch, D. Lightwolers and P. Greenwood, 1999. A new system for automatyic measurement of permanganate time. Laboratory Automation Inform. Manage., 34: 57-67. DOI: 10.1016/S1381-141X(99)00004-0

Janssen, A.J.H., G. Lettinga and A. de Keizer, 1999. Removal of hydrogen sulphide from wastewater and waste gases by biological conversion to elemental sulphur colloidal and interfacial aspects of biologically produced sulphur particles. Colloids Surfaces. 151: 384-397. DOI: 10.1016/S09277757(98)00507-X

Kamoun, P., 2004. Endogenous production of hydrogen sulphide in mammals. Amino Acids, 26: 243-254. DOI: $10.1007 / \mathrm{s} 00726-004-0072-\mathrm{X}$

Kato, S., Hirano, Y., Iwata, M., Sano, T., Takeuchi, K. and S. Matsuzawa, 2005. Photocatalytic degradation of gaseous sulfus compounds by silver-deposited titanium dioxide. Applied Catalysis, 57: 109-115. DOI: 10.1016/j.apcatb.2004.10.015

Lemley, A.T., J.J. Schwartz and L.P. Wagenet. 1999. Hydrogen sulphide in household drinking water. 329FS7 78/200 Rev. 1/99 1M MTS80063, Cornell University Cooperative Extension, Ithaca, New York: USA.

Li, L., A. Hsu and P.K. Moore, 2009. Actions and interactions of nitric oxide carbon monoxide and hydrogen sulphide in the cardiovascular system and in inflammation -a tale of three gases! Pharmacology and Therapeutics. 123: 386-400. DOI: 10.1016/j.pharma.thera. 2009.05.005
Lloyd, D., 2006. Hydrogen sulphide: clandestine microbial messenger? Trends in Microbiology 14: 456-462. DOI: 10.1016/j.time.2006.08.003

Lowicka, E. And J. Beltowski, 2007. Hydrogen sulphide $\left(\mathrm{H}_{2} \mathrm{~S}\right)$ : The third gas of interest for pharmacologists. Pharmacological Reports, 59: 4-24.

Macdonald, R., 2003. A handy device to monitor hydrogen sulphide levels. Better Pork. 93, Van Kleek Hill, Ontario, Canada.

Mellet, C., 2010. Municipal planning strategy: Beaver Bank, Hammonds Plains and Upper Sackville Halifax Regional Municipality, Halifax, Nova Scotia, Canada.

Montgomery, J.M., 1985. Water Treatment Principles and Design. 1st Edn., John Wiley and Sons, New York, ISBN: 0471043842, pp: 696.

NRC, 2008. Geological Survey of Canada: Mineral deposits of Canada, Natural Resources Canada, Ottawa, Ontario, Canada.

NSDH, 2009. The drop on water: Hydrogen sulphide. Nova Scotia Department of Health. Halifax, Nova Scotia.

Rinzema, A. and G. Lettinga. 1988. Anaerobic treatment of sulphite containing wastewater in Biotreatment Systems (Wise, D.L. Ed.). CRC Press, Boca Raton, Florida, USA. ISBN: 0-8493-4850-1

Sparling, J.H. and B.M. Hennick, 1974. The production of hydrogen sulphide in peats. Folia Microbiol., 19: 59-66. DOI: 10.1007/BF02874504

Thompson, M.A., U.G. Kelkar and J.C. Vickers, 1995. The treatment of ground water containing hydrogen sulphide using microfiltration. Desalination, 102: 287-291. DOI: 10.1016/00119164(95)00065-A

Tichy, R., A. Janssen, J.T.C. Grotenhuis, G. Lettinga and W. Rulkens. 1994. Possibilities for using biologically-produced sulphur for cultivation of thiobacilli with respect to bioleaching processes. Bioresource Technol., 48: 221-231. DOI: 10.1016/0960-8524(94)90150-3

Twibright, R., 2009. General Resistors, Ronja Twibright, Zurich, Switzerland.

Wellowner.org, 2009. Hydrogen Sulfide. National Ground Water Association. Westerville, Ohio, USA.

WHO, 2003. Hydrogen Sulfide in Drinking-water. Background document for development of WHO Guidelines for Drinking-water Quality. WHO/SDE/WSH/03.04/07. World Health Organization, Geneva, Switzerland.

Willey, B.F., H. Jennings and F. Muroski, 1964. Removal of hydrogen sulfide with potassium permanganate. J. Am. Water Works Association. 56: 475-479. 